\title{
Polymer-Based Smart Coatings for Comfort in Clothing
}

\author{
Scientific Review
}

Received 03-2016 • Accepted 04-2016

\begin{abstract}
This paper reviews the application of polymer-based smart coatings for obtaining active comfort regulation in clothing. Currently available systems for adaptive comfort regulation which involve application of phase change materials (PCMs), shape memory polymers (SMPs) and stimuli-responsive polymers (SRPs) have been briefly discussed. It is shown that functional activity (sense - react - adapt) of polymer-based smart textiles can provide active comfort regulation function to textile materials.

Keywords: smart coating; smart clothing; phase change materials; shape memory polymers; stimuli responsive polymers
\end{abstract}

\section{Introduction}

The use of textile material for human clothing is the most traditional area of textiles. In traditional way the protective role of clothing has been quite passive being restricted to choosing the proper material for certain physical conditions of the body and of the environment, with a simple task to keep the wearer comfortable and healthy. Nevertheless, throughout the human history the role of clothing has become much more complex as the consequence of the changes in lifestyle and the sophistication of consumer demands.

By being based on the expansion of education, technology, industry, urban life and communication tools, modern society comprises complex culture changing accompanied with increased social mobility, personal development opportunities and more autonomy given to the individuals. As the consequence, current consumer demands in clothing have become closely related to high performance and efficiency, especially within the areas of leisurewear, sportswear, workwear and PPE. The requirement that a clothing possesses an additional active role of adapting to the changes of physiological needs in accordance with the activity of the wearer and the changes in the environment is

Corresponding author: Prof. DrSc Dragan Jocić Phone: +381113303738

E-mail:drjoc@tmf.bg.ac.rs becoming increasingly emphasized. This novel functionality is known as "active comfort regulation" and it can be achieved by implementing the socalled "smart polymer coating technology". By applying smart polymers, textile materials that can sense and interpret changes in their local environment (temperature, humidity, $\mathrm{pH}$, etc.) and respond appropriately can be produced. When considering clothing, the term local environment comprises both the environmental conditions (outside) and the body functions (inside).

A wide variety of smart polymer coating technologies is currently being possible as the consequence of enormous growth in supporting technologies, primarily in the areas of surface modification techniques, stimuli-responsive polymers (SRPs), phase change materials (PCMs) and shape memory polymers (SMPs). By operating at micro- and nano-level, these technologies provide the means for restricting textile modification to a very thin layer of material surface. This approach enables producers to continue using conventional textile fibres to create modern smart textile materials that are not only keeping us warm, dry and comfortable, but are also expected to react and interact with a certain range of stimuli and situations.

Tekstilec, 2016, 59(2), 107-114

DOI: 10.14502/Tekstilec2016.59.107-114 


\section{Thermal Comfort Ability of Clothing}

Although there is no single determination of comfort, it is well known that thermal resistivity and moisture dissipation in all their forms play a significant role in providing overall comfort. Mecheels [1] has described wear comfort as a measure of how well a clothing assists the functioning of the body, or at least impairs it to a minimum degree. As a clothing is directly in contact with the human body, it interacts with the body continuously and dynamically during wear, which stimulates mechanical, thermal, and visual sensations. This has been termed by $\mathrm{Li}$ [2] as sensory comfort which is a relatively new area in clothing comfort research.

\subsection{Factors of Thermal Comfort in Clothing} In general, thermal comfort depends on the interaction between three sets of factors: environmental factors (air temperature, air motion, ambient air relative humidity and mean radiant temperature), physiological factors (e.g. metabolic heat) and clothing factors (insulation, permeability, design elements). Taking into consideration main factors of thermal comfort, it can be considered that proper insulation by clothing is obtained by ensuring thermal balance of the human body despite changes in the ambient temperature and humidity, as well as in the metabolic heat production as the result of the wearer's activity [3]. Generally, the perception of clothing comfort is positively related to warmth and negatively to dampness [4].

A key function of clothing in terms of thermal comfort is insulation. Clothing creates a certain microclimate around the human body, which is mostly determined by the volume of air enclosed in the fabric and between the fabric and the skin. Hence, the easiest way to achieve thermal comfort is to ensure that the insulation property of a clothing being worn is appropriate.

In achieving appropriate insulation, i.e. thermal comfort, breathability and moisture management of a garment are the most important parameters. Breathability and moisture management are closely interrelated. If clothing is not breathable, vapour and excess heat cannot escape from the body, thus limiting the ability of the wearer to maintain an ideal microclimate. Therefore, a clothing must be able to transport the moisture away from the skin and allow that the vapour passes through the fabric and evaporate to the ambient. The rate at which this process occurs determines how breathable textile material is.

Since a clothing creates certain microclimate around the human body, which affects the human feeling of comfort, the air temperature between the body and the first layer of clothing is the determining factor for comfort feeling. However, the optimum level of this temperature is determined by human physical activity, and it is greatly influenced by the level of health, age, physical fitness and general metabolism of any individual. The more intense the activity of the wearer is and the more extreme the environment conditions are, the higher is the impact of clothing on thermoregulation.

\subsection{Active vs. Passive Thermoregulation}

Based on the ability to respond to the environmental parameters changes, textiles with thermoregulation function could be divided into passive and active. The well-known passive thermoregulation property is present in conventional textiles (e.g. silk or wool) which are able to warm or cool depending on the environmental conditions. It can be achieved also with textiles made of special fibres (e.g. hollow fibres for warming) or with special textile structure (e.g. three-dimensional structure constructions), as well as with functional multilayer clothing systems (e.g. 1st layer - good vapour and air permeability; $2^{\text {nd }}$ layer - warmth isolation; $3^{\text {rd }}$ layer - protection from environmental conditions: wind, rain).

Active thermoregulation is achieved by the products with ability to optimise and assist thermoregulation capability of the wearer by providing conditions for warming the body when the temperature drops, or cooling it when the temperature rises, thus actively keeping the balance of the human body micro-climate temperature. The main challenge for active comfort regulation function is that it must be capable of supporting wide variety of microclimate variations caused by both environmental factors and physiological factors to enable spontaneous regulation of clothing performance in a desirable manner when environmental conditions change. Hence, responsive and adaptive functions of smart clothing must be capable of supporting the abrupt microclimate changes, especially during exercise or in extreme environmental (cold and heat) conditions. 


\section{Technologies for Active Comfort Regulation}

There are two main principles through which active thermoregulation functionality of textile fabrics can be achieved: (1) incorporation of the materials capable of absorbing and/or releasing heat; (2) incorporation of the materials capable of sensing temperature changes in the environment, and responding appropriately by adapting fabric insulation capability through providing changes in its breathability and moisture management (i.e. active permeability control). Both principles are involved in current smart polymer-based coating systems for active comfort regulation, which are based on the application of phase change materials (PCMs), shape memory polymers (SMPs) and stimuli-responsive polymers (SRPs). All these materials possess the ability to sense and react thermally, so they can be ranked as smart materials.

\subsection{Phase Change Materials (PCMs)}

Phase change materials (PCMs) are the substances that possess the ability to change their physical state for example, from a solid to a liquid - in response to temperature changes within a rather narrow temperature range. During phase transitions (i.e. as a phase change takes place) PCMs store, release or absorb energy in a form of latent heat. In simple words - PCMs are basically the materials that absorb lots of heat from their environment when it is warm and then release it when it becomes cold. The ability of PCMs to control the heat flow "in and out" makes them very suitable as a source of heat storage for active comfort regulation of textile materials and clothing [5-7].

In practice, when PCMs in a clothing are heated (by the wearer's activity or warm environment), they liquefy. During this process, PCMs absorb excess heat and create a cooling effect. As the body of the wearer cools down, PCMs change from a liquid to a solid state and release heat which keeps the wearer warm. In such a way, the clothing system can adapt by itself to variable thermal needs (i.e. the activity level of the wearer and the ambient temperature). This exciting property of PCMs is recognized as very useful in producing protective garments for all kinds of weather - from the strongest winter to the hottest summer. A wide spectrum of phase change materials is currently available, with different heat storage capacity and phase change temperature. For a suitable application of PCMs in textiles, the phase change temperature must be within a comfort range of humans, namely between 15 and $35^{\circ} \mathrm{C}$. PCMs that fulfil the above mentioned requirement are different kinds of paraffin waxes (mixture of mostly straight-chain $n$-alkanes) and linear long chain hydrocarbons (e.g. $n$-octadecane, $n$-hexadecane, $\mathrm{n}$-eicosane etc.), which are usually combined to give the desired physical properties and reach required temperature stability. Another important PCM for textile applications is low cost commercial paraffin wax polyethylene glycol (PEG) of variable molecular weight. Other attractive candidates for textile applications are: fatty acids and their binary mixtures, polyalcohols and polyalcohol derivatives and hydrated inorganic salts.

The major disadvantage for the application of PCMs in textile field is the need for containers to prevent the leakage of PCMs. Therefore, since PCMs are under certain conditions in liquid state, they are usually not directly applied to textile material, but they are mostly first encapsulated and further applied in the form of microcapsules - small polymeric spheres with diameters of only a few micrometres (typically they are $20-40 \mu \mathrm{m}$ in diameter) [8-9]. In their application to textile materials, PCM-microcapsules can be either permanently locked in fibre structure (applied during synthetic fibre forming spinning) or coated onto the surface of a textile structure (chemical finishing). For application of PCM-microcapsules by coating, a coating composition must be prepared, which includes PCM-microcapsules, a surfactant, a dispersant, an antifoam agent, and a polymeric mixture (as thickener and binder). An alternative method is incorporation of PCM-microcapsules in the form of continuous film to the textile material surface by using coating with polymers such as acrylic, polyurethane, etc. PCMs can be applied to textile material also by lamination. In that case PCM-microcapsules are incorporated into a thin polymer film which is in the next stage of production applied to the inner side of the fabric system by lamination process.

Apart from imparting active comfort regulation property to textile material, PCM-microcapsules can adversely affect other comfort-related properties of textiles, especially when coating results in drastic changes in the surface characteristics of materials as the consequence of the increased quantity of microcapsules applied. The fabric can become stiff and moisture-impermeable, consequently reducing fabric softness and 
flexibility, and impairing breathability and moisture transport properties. Therefore, the properties of fabrics treated with PCM-microcapsules need to be seriously assessed before use in a garment [10-11].

Thermally active materials made by PCM-microcapsules coating are able to improve wear comfort of a garment by active thermal insulation, i.e. by controlling the heat flux through the garment layers and adjusting it to the variable thermal circumstances (activity level and ambient conditions). The functionality of such material is based on a buffering effect that PCM-microcapsules have against temperature changes which provides an enhanced thermal capacity in addition to the existing passive insulation characteristic of the garment system. However, it must be noted that the clothing layer (or layers) containing PCMs must go through the transition temperature range before the phase change in PCMs occurs, and either release or absorb heat (depending on the ambient conditions). This means that the active comfort regulation cannot be achieved under steady-state thermal conditions, so the wearer has to impose some activity to cause the change of the temperature of the PCMs containing fabric. The need of PCMs for constant charging and recharging is the main reason that PCM-microcapsule coated clothing is mainly used for active wear, work wear and outdoor sports apparel.

\subsection{Shape Memory Polymers (SMP)}

Shape memory materials (SMMs) are a set of materials that, due to an external stimulus, can change their shape from some temporary deformed shape to a previously 'programmed' shape [12]. The shape change is activated most often by changes in the surrounding temperature, but with certain materials stress, magnetic field, electric field, $\mathrm{pH}$-value, UV light and even the presence of water can also be a triggering stimulus.

Among various available shape memory materials, shape memory polymers (SMPs) are suitable for producing smart coatings for textiles. Nevertheless, the shape memory effect of SMPs is not related to a specific material property of single polymers, but to specific polymer systems that possess shape memory properties. The shape memory effect results from a combination of the polymer structure and the polymer morphology together with the applied processing and programming technology [13-15]. The most readily available SMP for use in textiles is the segmented polyurethane (SMPU) system which is a two-phase heterogeneous structure consisting of a rigid fixed phase and a soft reversible phase. The reversed phase is used to hold the temporary deformation and the fixed phase is responsible for memorizing the permanent shape. The permanent shape can be memorized and recovered automatically from the temporary deformation with the trigger of heating [16].

Since the most common stimulus in SMP applications is heat (i.e. the change in the environmental temperature), the most often reported research on their application in textiles is for thermoregulation, i.e. active comfort control [17]. SMPs can be incorporated in the form of films in multilayer garments for protective clothing, sportswear or leisurewear. Using a composite film of shape memory polymer as interlining (i.e. membrane) in multilayer garments, outdoor clothing could have adaptable thermal insulation and be used as a performance clothing with variable - adaptable thermal insulation values [18]. The principle of active comfort regulation is based on the ability of SMP film (or coating) to undergo a large change in moisture permeability across the glass transition temperature $\left(\mathrm{T}_{\mathrm{g}}\right)$ or the soft segment crystal melting point temperature $\left(\mathrm{T}_{\mathrm{ms}}\right)$. Based on the $\mathrm{T}_{\mathrm{g}} / \mathrm{T}_{\mathrm{ms}}$ set at room temperature, the SMP can have low moisture permeability below the $\mathrm{T}_{\mathrm{g}} / \mathrm{T}_{\mathrm{ms}}$ (in the glassy state) and high moisture permeability above $\mathrm{T}_{\mathrm{g}} / \mathrm{T}_{\mathrm{ms}}$ (in the rubbery state). The same principle applies to SMP coated textiles. The permeability of a coated fabric changes as the wearer's environment and body temperature change. When the wearer's body temperature is low, the fabric remains less permeable, restricting the loss of body warmth and thus keeping the body warm. When the body temperature rises as the consequence of certain activity (and it starts sweating), the SMP coated textile allows the water vapour to escape into the environment (i.e. releasing heat to the environment) because its moisture permeability becomes very high with increasing body temperature.

As an alternative to the use of films and lamination, SMP can be directly used as a finishing agent (by coating) for application on textile fabrics. Nevertheless, the area of coating of SMP to textiles is relatively new and reported developments are scarce. One promising method is based on a highly adhesive resin coating solution by dissolving polyurethane SMP in dimethylacetamide [19] or grafting to cotton [20-21] and wool [22] fabrics. The coating process is reported as being highly efficient as already a small content of 
SMP is sufficient to transfer the shape memory effect to the fabric. Hu et al. [23] proposed the general mechanism for coating textile with SMP, based on the cross-linking between the SMP network itself and the fibre, which can form the net-points and the soft segments of SMP serve as switches. Thus, the shapememory effect from SMP can be transferred to the fabric and maintain its durability during washing.

Currently, the application of SMPs on fabrics/garments to develop smart textiles is a very promising area, which has tremendous potential. It has attracted enormous attention, but technologically it can be still considered very challenging.

\subsection{Stimuli-Responsive Polymers (SRPS)}

One of the approaches to obtain active comfort regulation in smart textiles is based on the use of stimuli-responsive polymer (SRP) coatings integrated into the fabric structure. The main challenge of this approach is to integrate SRP durably to textile material surface in such a manner that they still retain the responsive behaviour.

In recent times, an increasing amount of research has been done on functional finishing of textile materials by incorporating stimuli-responsive polymeric systems. Hu et al. [24] comprehensively elucidated the applications of SRPs in the textile and clothing sector, together with the assessment of the associated constraints in fabrication processes for textiles and their potential applications in the near future. Another extensive review deals with the temperature responsive SRPs and their application in textiles [25]. Both reviews give special attention to the systems for improving comfort in clothing by active comfort regulation and, apart from reviewing possibilities of PCMs and SMPs, pay special attention to the thermal/pH-responsive polymeric hydrogels.

Hydrogels are widely used in a variety of applications and are usually defined as three-dimensional crosslinked polymeric networks that can imbibe large amounts of water [26-27]. If hydrogel is prepared from stimuli-responsive polymers, it adds functionality and displays changes in solvation in response to certain stimuli such as temperature, $\mathrm{pH}$, ionic strength, light, and electric field. Hydrogels responsive to temperature and $\mathrm{pH}$ have been the most widely studied systems since these two factors have a physiological significance. Versatile dual responsive hydrogels have been reported mainly for biomedical applications and the numbers of reviews coming up in this area in recent times address the latest developments [27-30]. The fact of special interest for the application in smart textiles is that responsive hydrogel exhibits specific volume phase-transition (swelling and shrinking) properties which can be triggered by various stimuli (temperature, $\mathrm{pH}$, humidity etc.). Incorporation of responsive hydrogels (i.e. microgels) to the surface of textile materials enables switching (on/off) of various properties of a material [31]. Currently, most of the studies of synthetic temperature-responsive polymers focus on poly(N-isopropylacrylamide), poly(N-alkylacrylamide), poly(N-vinylcaprolactam), poly(vinylmethyl ether) and their derivatives [32]. Among these polymers, poly(N-isopropylacrylamide) (poly-NiPAAm) is the most widely explored as it has the peculiarity of possessing LCST (a reversible coil to globule transition in solution when the temperature is set beyond the so-called lower critical solution temperature) in the physiological range $\left(\sim 32{ }^{\circ} \mathrm{C}\right)$, which is notably important for biomedical or clothing applications [30, 33].

The origin of poly-NiPAAm temperature sensitivity has been fully explained by the cooperative hydration mechanism [34]. Below LCST, the amide group binds water molecules via hydrogen bonding (i.e. it hydrates to form an expanded structure); above LCST, hydrogen bonds break and the polymer expels water and precipitates (i.e. its chains dehydrate to form a shrunken structure). The result of copolymerization of poly-NiPAAm with an ionisable polymer, such as chitosan, is a microgel that is responsive to both temperature and $\mathrm{pH}$. However, because of its hydrophilic nature (affected by $\mathrm{pH}$ ), the incorporation of chitosan bearing a large amount of hydrophilic groups into the poly-NiPAAm hydrogel network is expected to greatly influence the above explained interactions.

It has been shown that efficient incorporation of the surface modifying system based on responsive polyNiPAAm/chitosan microgel (PNCS) into a textile material (cotton or polyester) can be done from aqueous microgel dispersion by simple pad-dry or paddry-cure procedure. Microgel could impart responsive moisture management properties to cotton, transforming it to an advanced material which could improve wear comfort when used for clothing [3536]. SRP microgel particles are confirmed to exhibit a reversible phase transition (expansion - contraction) by varying their size more than threefold between temperature above and below LCST [37]. Once incorporated into textile material surface, it is likely that 
the SRP microgel particles act as a sensor of temperature and as a valve to regulate the water vapour permeability of the fabric, thus enabling control of moisture content and moisture transmission properties of a modified fabric with small temperature variation in the physiological range. Since moisture permeability is the most important criteria to evaluate textile fabric comfort ability, the water vapour transmission (WVT) values for cotton and PES fabrics coated with poly-NiPAAm/chitosan microgel at low and high relative humidity (R.H.) and temperatures below and above LCST of the microgel have been measured [3841]. The studies of other research groups with similar microgel system have shown temperature-responsiveness of cotton fabric in terms of higher WVT values at higher temperature [42-43].

Since water presence is the driving force for temperature responsiveness of microgel, different behaviour can be observed at low and high relative humidity (R.H.). At low R.H. values (50\% and 65\%), since there is not enough ambient humidity available, the microgel particles are in "dry" state and the modified textile fabrics do not show obvious temperature response (or at least it is not macroscopically observable), thus showing very similar behaviour to untreated material. However, at high R.H. values $(80 \%, 90 \%$ or $95 \%)$, when enough humidity is available, there are noticeable differences in the modified textile fabrics behaviour in response to temperature change. Even though the differences in WVT can be considered as rather small, they clearly imply the responsive property of materials coated with microgel particles. Nevertheless, the WVT values confirm that the moisture permeability of coated fabrics is not present continuously (i.e. passively), but it could be activated "on demand" by sensing the stimuli (temperature and humidity) in immediate surroundings, thus reacting to the human activity level or changing ambient conditions.

These properties can meet the demands for improved water vapour permeation at higher temperature and humidity for use in clothing and can be considered as an important step in the development of materials for the so-called "responsive performance apparel".

\section{Conclusion}

Polymer-based smart coatings currently provide great potential in obtaining textile materials, i.e. clothing with active comfort regulation properties.
Thermally active materials made by applying PCMmicrocapsule coating are able to improve wear comfort of a garment by active thermal insulation, i.e. by controlling the heat flux through the garment layers and adjusting it to the variable thermal circumstances (activity level and ambient conditions). The processes of active permeability control in the SMP and SRP coated textiles are based on their ability to act as a switch to control the transmission of water vapour. The wearer's comfort can be improved if the material possesses high water vapour permeability at higher temperature and low water vapour permeability at lower temperature. At temperatures below the switching temperature, the SMP/SRP coating on the material surface exists in glassy/expanded state, while at higher temperatures it exists in a rubbery/collapsed state. Thus, the SMP/SRP coated fabrics could have water vapour permeability controlled by closing and opening the permitting passages for the water vapour transport through the material as the consequence of drastic polymer changes with the variation of temperature. By blocking the pores, they could also form a physical barrier to wind and water, which could be very useful for rainwear and foul weather clothing.

The potential future benefits of apparel adaptive comfort regulation by smart coatings involving application of phase change materials (PCMs), shape memory polymers (SMPs) and stimuli-responsive polymers (SRPs) are significant. Hence, the use of the polymerbased smart coatings for improvement of comfort will undoubtedly continue to expand into apparel applications. Nevertheless, all available technologies do have their limitations and still have potential to develop.

\section{References}

1. MECHEELS, Jürgen. Körper-Klima-Kleidung: Wie funktioniert unsere Kleidung. Berlin : Schiele \& Schön; 1998, 19-30.

2. LI, Yi. The science of clothing comfort. Textile Progress, 2001, 31(1-2), 1-135, doi: 10.1080/ 00405160108688951.

3. TUĞRUL OĞULATA, Ramazan. The effect of thermal insulation of clothing on human thermal comfort. Fibres \& Textiles in Eastern Europe, 2007, 15(2), 67-72.

4. LI, Yi. Perceptions of temperature, moisture and comfort in clothing during environmental 
transients. Ergonomics, 2005, 48(3), 234-248, doi: 10.1080/0014013042000327715.

5. GEETHAMALINI, R. The role of phase change material in textiles. Melliand International, 2006, 12(2), 118-121.

6. MONDAL, Subrata. Phase change materials for smart textiles - An overview. Applied Thermal Engineering, 2008, 28(11-12), 1536-1550, doi: 10.1016/j.applthermaleng.2007.08.009.

7. SARIER, Nihal, ONDER, Emel Organic phase change materials and their textile applications: An overview. Thermochimica Acta, 2012, 540, 7-60, doi: 10.1016/j.tca.2012.04.013.

8. NELSON, Gordon. Application of microencapsulation in textiles. International Journal of Pharmaceutics, 2002, 242(1-2), 55-62, doi: 10.1016/s0378-5173(02)00141-2.

9. SARIER, Nihal, ONDER, Emel. The manufacture of microencapsulated phase change materials suitable for the design of thermally enhanced fabrics. Thermochimica Acta, 2007, 452(2), 149160, doi: 10.1016/j.tca.2006.08.002.

10. SHIN, Younsool, YOO, Dong-Il, SON, Kyunghee. Development of thermoregulating textile materials with microencapsulated phase change materials (PCM). IV. Performance properties and hand of fabrics treated with PCM microcapsules. Journal of Applied Polymer Science, 2005, 97(3), 910-915, doi: 10.1002/app.21846.

11. YING, Bo-an, KWOK, Yi-LI, LI, Yi, ZHU, Qingyong, YEUNG, Chap-yung. Assessing the performance of textiles incorporating phase change materials. Polymer Testing, 2004, 23(5), 541549, doi: 10.1016/j.polymertesting.2003.11.002.

12. HONKALA, M. Introduction to shape memory materials. In: Intelligent textiles and clothing. Edited by Heikki Mattila. 2006. Cambridge : Woodhead Publishing, 85-103, doi: 10.1533/ 9781845691622.2.85.

13. LENLEIN, Andreas, KELCH, Steffen. Shapememory polymers. Angewandte Chemie International Edition, 2002, 41(12), 2034-2057, doi: 10.1002/1521-3773(20020617)41:12<2034:aidanie2034>3.0.co;2-m.

14. MENG, Herper, LI, Guoqiang. A review of stimuli-responsive shape memory polymer composites. Polymer, 2013, 54(9), 2199-2221, doi: 10.1016/j.polymer.2013.02.023.

15. LIU, C., QIN, H., MATHER, P.T. Review of progress in shape-memory polymers. Journal of
Materials Chemistry, 2007, 17(16), 1543-1558, doi: 10.1039/b615954k.

16. HU, Jinlian. Shape memory textiles. In: Shape memory polymers and textiles. Edited by J. Hu. Cambridge : Woodhead Publishing, 2007, 305337, doi: 10.1533/9781845693060.305.

17. HU, J., MONDAL, S. Temperature sensitive shape memory polymers for smart textile applications. In: Intelligent textiles and clothing. Edited by Heikki Mattila. Cambridge : Woodhead Publishing, 2006, 104-123, doi: 10.1533/ 9781845691622.2.104.

18. HU, J., MONDAL, S. Study of shape memory polymer films for breathable textiles. In: Intelligent textiles and clothing. Edited by Heikki Mattila. Cambridge : Woodhead Publishing, 2006, 143-164, doi: 10.1533/9781845691622.2.143.

19. STYLIOS, George K. Engineering textile and clothing aesthetics using shape changing materials. In: Intelligent textiles and clothing. Edited by Heikki Mattila. Cambridge : Woodhead Publishing, 2006, 165-189, doi: 10.1533/ 9781845691622.2.165.

20. LIU, Yeqiu, HU, Jinlian, ZHU, Yong, YANG, Zhuohong. Surface modification of cotton fabric by grafting of polyurethane. Carbohydrate Polymers, 2005, 61(3), 276-280, doi: 10.1016/j. carbpol.2005.03.010.

21. LIEM, H., YEUNG, Lapyan, HU, Jinlian. A prerequisite for the effective transfer of the shape-memory effect to cotton fibers. Smart Materials and Structures, 2007, 16(3), 748753, doi: 10.1088/0964-1726/16/3/023.

22. DONG, Zheng-E., HU, Jinlian. The performance evaluation of the woven wool fabrics treated with shape memory polymers. International Journal of Sheep and Wool Science, 2008, 56(1), 9-18.

23. HU, Jinlian, ZHU, Yong, HUANG, Huahua, LU, Jing. Recent advances in shape-memory polymers: Structure, mechanism, functionality, modeling and applications. Progress in Polymer Science, 2012, 37(12), 1720-1763, doi: 10.1016/j. progpolymsci.2012.06.001.

24. HU, Jinlian, MENG, Harper, LI, Guoqiang, IBEKWE, Samuel I. A review of stimuli-responsive polymers for smart textile applications. Smart Materials and Structures, 2012, 21(5), 1-23, doi: 10.1088/0964-1726/21/5/053001.

25. CRESPY, Daniel, ROSSI, M. René. Temperature-responsive polymers with LCST in the 
physiological range and their applications in textiles. Polymer International, 2007, 56(12), 1461-1468, doi: 10.1002/pi.2277.

26. PEPPAS, Nikolaos A., KHARE, Atul R. Preparation, structure and diffusional behaviour of hydrogels in controlled release. Advanced Drug Delivery Reviews, 1993, 11(1-2), 1-35, doi: 10.1016/0169-409x(93)90025-y.

27. KOPECEK, Jindřich, YANG, Jiyuan. Hydrogels as smart biomaterials. Polymer International, 2007, 56(9), 1078-1098, doi: 10.1002/pi.2253.

28. KUMAR, Ashok, SRIVASTAVA, Akshay, GALAEV, Igor, MATTIASSON, Bo. Smart polymers: Physical forms and bioengineering applications. Progress in Polymer Science, 2007, 32(10), 12051237, doi: 10.1016/j.progpolymsci.2007.05.003.

29. MANO, João F. Stimuli-responsive polymeric systems for biomedical applications. Advanced Engineering Materials, 2008, 10(6), 515-527, doi: 10.1002/adem.200700355.

30. PELTON, Robert. Temperature-sensitive aqueous microgels. Advances in Colloid and Interface Science, 2000, 85(1), 1-33, doi: 10.1016/ s0001-8686(99)00023-8.

31. JOCIĆ, Dragan. Smart Textile materials by surface modification with biopolymeric systems. Research Journal of Textile and Apparel, 2008, 12(2), 58-65, doi.org/10.1016/s0001-8686(99)00023-8.

32. LIU, Ruixue, FRAYLICH, Michael, SAUNDERS, Brian R. Thermoresponsive copolymers: From fundamental studies to applications. Colloid and Polymer Science, 2009, 287(6), 627-643, doi: 10.1007/s00396-009-2028-x.

33. SCHILD, H.G. Poly(N-isopropylacrylamide): experiment, theory and application. Progress in Polymer Science, 1992, 17(2), 163-249, doi: 10.1016/0079-6700(92)90023-r.

34. OKADA, Yukinori, TANAKA, Fumihiko. Cooperative hydration, chain collapse, and flat LCST behavior in aqueous poly( $\mathrm{N}$-isopropylacrylamide) solutions. Macromolecules, 2005, 38(10), 4465-4471, doi: 10.1021/ma0502497.

35. KULKARNI, Amit, TOURRETTE, Audrey, WARMOESKERKEN, Marijn. M. C. G., JOCIĆ, Dragan. Microgel-based surface modifying system for stimuli-responsive functional finishing of cotton. Carbohydrate Polymers. 2010, 82(4), 1306-1314, doi: 10.1016/j.carbpol.2010.07.011.

36. TOURRETTE, Audrey, De GEYTER, Nathalie, JOCIĆ, Dragan, MORENT, Rino, WARMOES-
KERKEN, Marijn M. C. G., LEYS, Chistophe. Incorporation of poly( $\mathrm{N}$-isopropylacrylamide $) / \mathrm{chi}$ tosan microgel onto plasma functionalized cotton fibre surface. Colloids and Surfaces A: Physicochemical and Engineering Aspect, 2009, 352(1-3), 126-135, doi: 10.1016/j.colsurfa.2009.10.014.

37. JOCIĆ, Dragan, TOURRETTE, Audrey, GLAMPEDAKI, P., WARMOESKERKEN, Marijn M. C. G. Application of temperature and $\mathrm{pH}$ responsive microhydrogels for functional finishing of cotton fabric. Materials Technology: Advanced Performance Materials, 2009, 24(1), 14-23, doi: 10.1179/175355509x417963.

38. KRIŽMAN LAVRIČ, Pavla, WARMOESKERKEN, Marijn M. C. G., JOCIĆ, Dragan. Functionalization of cotton with poly-NiPAAm/chitosan microgel. Part I. Stimuli-responsive moisture management properties. Cellulose, 2012, 19(1), 257-271, doi: 10.1007/s10570-011-9632-x.

39. KRIŽMAN LAVRIČ, Pavla, TOMŠIČ, Brigita, SIMONČIČ, Barbara, WARMOESKERKEN, Marijn M. C. G., JOCIĆ, Dragan. Functionalization of cotton with poly-NiPAAm/chitosan microgel: Part II. Stimuli-responsive liquid management properties. Cellulose, 2012, 19(1), 273-287, doi: 10.1007/s10570-011-9635-7.

40. GLAMPEDAKI, Pelagia, DUTSCHK, Victoria, JOCIĆ, Dragan, WARMOESKERKEN, Marijn M. C. G. Functional finishing of aminated polyester using biopolymer-based polyelectrolyte microgels. Biotechnology Journal, 2011, 6(10), 1219-1229, doi: 10.1002/biot.201100115.

41. TOMŠIČ, Brigita. Modification of PES fabric by stimuli responsive microgel using sol-gel technology. In: Surface modification systems for creating stimuli responsiveness of textiles. Edited by Dragan Jocić. Enschede: University of Twente, 2010, 107122. [online] [Accessed: 30. 03. 2015]. Available on World Wide Web: <http://www.utwente.nl/ $\mathrm{ctw} / \mathrm{efsm} /$ advanbiotex/workshop/proceedings/>.

42. WANG, Weiling, YU, Weidong. Preparation and characterization of CS-g-PNIPAAm microgels and application in a water vapour-permeable fabric. Carbohydrate Polymers, 2015, 127, 1118, doi: 10.1016/j.carbpol.2015.03.040.

43. BASHARİ, Azadeh, HEMMATİ NEJAD, Nahid, POURJAVADİ, Ali. Effect of stimuli-responsive nano hydrogel finishing on cotton fabric properties. Indian Journal of Fibre \& Textile Research, 2015, 40, 431-436. 